\title{
Medicinal Plants to be Saved and Research Work to be Done in Right Direction
}

\section{Ashoke K Ghosh*}

Professor, School of Pharmaceutical Sciences, IFTM University, Moradabad, UP, India

*Corresponding Author: Ashoke K Ghosh, Professor, School of Pharmaceutical Sciences, IFTM University, Moradabad, UP, India.

Received: August 20, 2019; Published: September 01, 2019

DOI: 10.31080/ASPS.2019.03.0388

Most of the plants related research works in India are polluting the environment directly. In one side, going beyond our need, large and very large quantity of plant materials we are using and on the other hand every day in the name of research work huge amount of organic solvents which are used to do extraction are drained out in the environment. As a result important medicinal plants particularly of big sizes are going to be extinct and in some cases certain species are already in extinct state. But plants must be saved if we would like to maintain the existence of human or living beings. Some points related to plants to be considered as below:

1. Whether we need to save the plants (out rightly the medicinal plants)?

2. Whether our approaches to do research work with plants in present days are in right path or direction?

3. Medicinal quality of herbs is to be judged on the basis of work in simulation with the process by which the active ingredients from plant materials are absorbed into our bodies.

4. What are those active ingredients responsible to provide the therapeutic activity of the plant?

5. Isolation and computational chemistry may lead to discover the new drugs for future.

Certainly to save the plants a great measure must be taken by us and one of the most effective methods may be the plant tissue culture. The particular plant-tissue (the part which is used and described in ancient literatures, like Ayurveda/Unani, etc.) where the desired or specified active ingredients are stored may be cultivated in plant tissue culture laboratory.

It is to be mentioned also that the most of the research works with plants are not in right direction. In most of the works we use organic solvents in first stage to extract the contents present in the desired part or parts expecting to check the activity already known to us ethnologically or from ancient books and most of the time successive extraction is done. This is completely a wrong process and we must not do. Furthermore generally the used solvents are discarded into the environment making the environment polluted.
We are to think over it for searching the other options to get the contents of the concerned part in intact condition. If our initial stage of research work is not the correct one, we can assume what will be the fate of the rest part of journey of research work.

Let us see the fate of herbal medicine either alone or with excipients mentioned in ancient literature or not when taken orally. In the first phase of its journey it crosses the buccal cavity where it comes in contact with the juices having enzymes or anything else known to us. Comes down then through oesophagus to stomach, mixed up with bile and other materials. From there, through intestine etc. it passes with its schedule timings and that may differ from person to person. So, to assess the release pattern and the active ingredient if any a similar environment to be created and kinetics to be judged then. A total simulation work is needed to get a clear profile of the herbs or medicinal plants.

By creating the same simulative condition now we can search for the ingredients that may be released and absorbed from the medicines or medicinal parts of the plant when administered orally. In that way the isolated material may be placed for pharmacological activities or through computational chemistry the investigation may be continued for further new innovative molecules. Accordingly the semisynthetic method may also show us new vista for future. As a whole we must take right direction of our research works otherwise in every time the work will mislead us.

The plant material here will be the specific tissue part produced in the tissue culture lab where side by side the effort will be kept continued to produce more and more bio-active ingredients by taking expertise from bio-technologists. In this way with the right process plants will be saved and research work also would be in right path.

\section{Volume 3 Issue 10 October 2019 (C) All rights are reserved by Ashoke K Ghosh.}

